\title{
Do People Care about Social Context? Framing Effects in Dictator Games
}

\author{
Anna Dreber \\ Stockholm School of Economics \\ Tore Ellingsen \\ Stockholm School of Economics \\ Magnus Johannesson \\ Stockholm School of Economics \\ David G. Rand \\ Harvard University
}

This version: 13 September 2011

SSE/EFI Working Paper Series in Economics and Finance No 738

\begin{abstract}
Many previous experiments document that behavior in multi-person settings responds to the name of the game and the labeling of strategies. Usually these studies cannot tell whether frames affect preferences or beliefs. In this Dictator game study, we investigate whether social framing effects are also present when only one of the subjects makes a decision, in which case the frame may only affect preferences. We find that behavior is insensitive to social framing.
\end{abstract}

Acknowledgement: Thanks to Rachel Sheketoff, Nils Wernerfelt and Xiaoqi Zhou for research assistance. Financial support from the Jan Wallander and Tom Hedelius Foundation and the Swedish Research Council is gratefully acknowledged, and DGR is supported by a grant from the John Templeton Foundation. 


\section{INTRODUCTION}

The power of economic theory derives partly from its parsimonious description of human motivation. Relying on the assumption that people's preferences are stable, an approach most stoutly defended by Becker and Stigler (1977), economists have built a simple, coherent, and general model of human behavior.

But critics argue that the simplicity and coherence has come at a high price: Preference stability is just too unrealistic an assumption. Social framing effects are considered to furnish a particularly striking example of unstable preferences. A large number of experiments document that behavior in elementary social settings, such as the Prisoners' dilemma, depends on details such as the name that the experimenters have given to the game, or the labeling of the strategies. For example, subjects cooperate more when the situation is called the Community Game than when it is called the Wall Street Game (Liberman, Samuels, and Ross, 2004; Kay and Ross, 2003). ${ }^{1}$

If preferences are so delicately sensitive to context, the external validity of preference data in general, and experimental data in particular, is gravely in doubt (see, e.g., Levitt and List, 2007, and references therein). In view of social framing effects, it has been argued that conventional decision theory must be complemented by radically different approaches, involving concepts such as "role theory" (Montgomery, 1998), "team reasoning” (Bacharach 1993, 1999; Sugden, 1993), and "the logic of appropriateness" (March, 1994; Weber et al, 2004). That is, if preferences are to be viewed as stable at all, they must be much richer than Becker and Stigler envisaged.

However, as noted by Fehr and Schmidt (2006) and Rabin (1998) among others, the presence of social framing effects does not prove that preferences are sensitive to context. The experimental evidence is also consistent with the alternative explanation that social context

\footnotetext{
${ }^{1}$ See also Andreoni (1995), Brewer and Kramer (1986), Cookson (2000), Ellingsen et al (2011), McDaniel and Sistrunk (1991), McCusker and Carnevale (1995), Pillutla and Chen (1999), Sell and Son (1997), Sonnemans, Schram, and Offerman (1998), van Dijk and Wilke (2000), and Zhong, Loewenstein, and Murnighan (2007). There are also some studies that fail to find the expected social framing effects, notably Brandts and Schwieren (2009), Cubitt, Drouvelis, and Gächter (2011), Dufwenberg, Gächter and Hennig-Schmidt (2011), and Rege and Telle (2004). However, in Rege and Telle (2004) the effect size is large, so the lack of statistical significance might be due to a small sample, and Dufwenberg, Gächter and Hennig-Schmidt (2011) have inadvertently, but instructively, used ambiguous social frames. Most of the above works consider relatively "light" social framing, i.e., manipulations of labels only. The earliest studies, by Deutsch $(1958,1960)$, apply "heavy" social framing, with more outspoken demands on behavior.
} 
serves as a coordination device - entering subjects' beliefs rather than their preferences. ${ }^{2}$ Indeed, after finding that social framing effects disappear when the Prisoners' dilemma is played sequentially, Ellingsen et al (2011) suggest that social framing effects in the Prisoners' dilemma work primarily through beliefs. ${ }^{3}$

In this paper, we investigate the preference channel more directly, by varying the social frame in a Dictator game. As the recipient has no move, we know that any effect on dictator behavior must come through the dictator's preferences.

To the best of our knowledge, there is no previously published study of social framing effects in Dictator games. ${ }^{4}$ But several researchers have thought about the idea, and the conventional wisdom is that behavior will respond significantly. ${ }^{5}$ For example, discussing the pros and cons of “neutrally” framed experiments, Loewenstein (1999, p.F31) writes:

\section{[i]t would be easy, through a suitable manipulation of context, to design a dictator study in which people would give none of their}

\footnotetext{
${ }^{2}$ If people care only about the own material payoff, beliefs should play no role in a Prisoners' dilemma. However, various common forms of altruism and reciprocity suffice to map a material Prisoners' dilemma into a game with multiple equilibria; see Ellingsen et al (2011) for formalities.

${ }^{3}$ Relatedly, Cubitt, Drouvelis, and Gächter (2011) study the impact of framing on punishment and emotions in a one-shot social dilemma with and without punishment. They find no evidence that the frame affects punishment behavior or emotions, leading them to conclude that social preferences are relatively stable. However, the framing effect on initial contributions is also insignificant in their study.

${ }^{4}$ In the concluding section, we discuss the closely related unpublished study by Suvoy (2003), which was recently brought to our attention by Sujoy Chakravarty. There we also discuss the findings of Leliveld, van Dijk, and van Beest (2008) concerning framing effects in Ultimatum games. For completeness, let us here also mention one additional related study. Keysar et al (2008) ostensibly let pairs of subjects play a sequence of two Dictator games, with some pairs acting under a "give" frame and other pairs under a "take" frame. Leaving aside the problem that an even allocation of the money can be attained after any decision by the first mover, the experiment must be interpreted with caution for several reasons. First, only one participant is being paid. Thus, at most one of the subjects in a pair will be playing with real money. When the first mover chooses an even split rather than to keep all the money, this could thus be seen as an implicit suggestion of mutual insurance. Due to risk aversion, both players getting 50 is preferable to both players having an even chance of 100 and 0 . Second, the experiment involves severe deception: In fact, there is no first mover. All subjects are second movers, being led to believe that the first mover chose an even split. Apparently many of the participants anticipated being deceived, as data for ten of the fifty participants in the relevant experiment were excluded because these participants didn't believe that there was a second mover. Clearly, the study violates the norm against deception that is currently enforced in economics. That objection aside, as subjects were clearly suspicious that they were being deceived, their behavior is difficult to interpret.

${ }^{5}$ Besides the evidence that social frames matter in multi-person games, there is evidence that other sorts of frames can matter in single-person decision problems. For example, in a seminal study, Tversky and Kahneman (1981) showed that people's ranking of lotteries depend on whether outcomes are framed as gains or losses. For a survey of individual choice effects of wording, see Levin, Schneider, and Gaeth (1998). For a suggestion how to take account of framing effects in decision theory, see Salant and Rubinstein (2008).
} 
money to a stranger, or one in which most people would give all of their money away.

Likewise, Fehr and Schmidt (2006, p.659) argue:

While the experimental results on ultimatum games are fairly robust, the dictator game seems to be a rather fragile situation in which minor factors can have large effects.

At the outset, these were our priors too.

We conduct two studies. In the first study, we let dictators either move money from their "own" envelope (give) or move money from the "other's" envelope (take). The dictator is completely anonymous to the recipient as well as to the experimenter, but in one pair of treatments the recipient learns about the game whereas in the other treatment the recipient does not learn at all where the money, if any, comes from. We hypothesized that the dictator would be relatively averse to taking, as this could be seen as violating the other's entitlement, and that the recipient would thus get more money in the take treatment, especially when recipients learn about what has happened. Although there are tendencies in the hypothesized direction, effect sizes are economically tiny and statistically insignificant.

The second study is designed with two objectives in mind. First, we seek to remove confounds that may cloud inference in the first study. For example, the label "taking game” may to some subjects have justified violating the other's entitlement. Therefore, in the second study we only manipulate the name of the game and the strategy labels, not the entitlement. In the lightest pair of frames, one game is called the Giving Game and the other is called the Keeping Game, but actions are given a neutral label, "transfer". In the heavier pair of frames, the corresponding actions are called "give" and "keep" respectively. Second, we desire a large enough sample size to ensure that any economically significant difference is also statistically significant. To collect such a large sample, we use the online labor market Amazon Mechanical Turk, henceforth MTurk, to conduct the experiment electronically (For a description and discussion of MTurk, we refer to Horton et al., In press.) However, even with about 200 subjects per treatment, social framing effects are so small as to remain statistically insignificant. 
As MTurk is a new technology for performing economic experiments, one might wonder whether if the lack of significant effects in Study 2 is the result of some limitation of the MTurk platform. To demonstrate that this is not the case, and that MTurk experiments are able to detect framing effects where they do exist, we perform a replication experiment, described in Appendix A. Consistent with previous results in the physical lab (Liberman, Samuels, and Ross, 2004; Kay and Ross, 2003), we find that in a one-shot Prisoners’ dilemma on MTurk, calling the game the 'Community Game' results in significantly more cooperation than when the game is called the 'Profit Game.'

Our conclusion is that preferences in Dictator games, at least in our subject pools, are largely immune to mere labeling of games and strategies. The finding supports the hypothesis that social frames primarily affect behavior through beliefs rather than preferences.

\section{THEORY}

Before discussing social framing effects, it is useful to consider which model best explains the wealth of existing Dictator game data. ${ }^{6}$ We shall not here attempt a complete survey of the various approaches to modeling social preferences; see Camerer (2003), Fehr and Schmidt (2006), and Sobel (2005) for surveys, and Andreoni and Miller (2002) for an empirical study that links up with conventional choice theory. ${ }^{7}$ But it is noteworthy that several recent proposals revolve around the hypothesis that societies have norms governing the sharing of joint windfalls, and that people trade-off their material benefit against compliance with the social norm; see in particular Andreoni and Bernheim (2009), Konow (2010), and Krupka and Weber (2010). ${ }^{8}$ To the extent that norm compliance is observable, it is now also quite clear that people factor their social esteem or image into the decision.

As Andreoni and Bernheim (2009) show, in somewhat different notation, the following utility function captures many of the observed Dictator game regularities:

\footnotetext{
${ }^{6}$ At the time of writing, the literature on Dictator games comprises more than 120 published articles; see Engel (2011) for a recent survey.

${ }^{7}$ Recall that Becker and Stigler (1977), while defending preference stability, never insisted that people ought to be seen as selfish materialists. To the contrary, throughout his career, Gary Becker has been a leading advocate of social preferences. His models are populated with agents having tastes for (out-group) discrimination as well as (ingroup) altruism. See, e.g., Becker (1974).

${ }^{8}$ It is quite clear that people are more prone to share windfalls than earned money (e.g., Cherry, Frykblom and Shogren, 2002), and it is likely that this is due to social norms that distinguish the two situations (Cappelen et al, 2007).
} 


$$
U_{i}=u(1-s, m)+\eta_{i} v(s-1 / 2)
$$

where $s$ is the share of the windfall that is given to the recipient, $1 / 2$ is the social norm (the ideal gift) concerning how to split a windfall gain, $\eta_{i}$ is a parameter that indexes how strongly a dictator of type $i$ cares about complying with the norm, and $m$ is the dictator's social image which is given by (the dictators belief about) the recipient's belief about $\eta$, conditionally on the dictator's choice of $s$. The sub-utility functions $u$ and $v$ are assumed to be concave in (1-s) and $s$ respectively, but while $u$ is everywhere increasing in both arguments, $v$ attains a maximum at $s=1 / 2$. Heterogeneity in behavior is here explained by the assumption that people differ in their norm-compliance parameter $\eta$.

Due to the concern for social image, $m$, Andreoni and Bernheim's utility function implies that the Dictator game is essentially a signaling game, and in order to make precise predictions about behavior one must significantly refine the set of Bayesian Nash equilibria. Under appropriate refinements, such as D1, the actual distribution of $\eta$ in the population is relatively unimportant for the qualitative results. Instead, the key is that a larger $\eta$ only induces larger gifts $s$ up to the point that $s=1 / 2$. Thus, even if the social image concern is strong, people stop giving at that point. In this way, the model explains the large frequency of equal splits without assuming that the utility function has a kink at this point. The model also explains the very low frequency of gifts just below $1 / 2$ and just above 0 .

Since people are concerned about their social esteem, the model can furthermore explain why the degree of dictator anonymity matters (Hoffman et al, 1994). Likewise, the model explains why people are willing to pay for quietly exiting the Dictator game rather than going through with their initial allocation, as documented by Dana, Cain, and Dawes (2006); see also Broberg, Ellingsen, and Johannesson (2007) and Lazear, Malmendier, and Weber (2010). As Andreoni and Bernheim (2009) show, people are also more prone to give small amounts when the recipient is informed that small gift could have come about by chance - due to circumstances beyond their control; see also Tadelis (2008). Plainly, the loss of esteem is smaller when the recipient cannot infer from a small gift that the dictator is selfish.

In addition to the above evidence, which Andreoni and Bernheim themselves explicitly address, we would like to add that their model is also capable of explaining the findings by 
Bardsley (2008) and List (2007), who both show that the introduction of additional "taking" options for the dictator reduces giving. Even if the ideal behavior $s=1 / 2$ is the same, the greediest option now involves taking, which means that a smaller gift suffices to separate oneself from the most selfish types. As far as we know, this point has not been made before. ${ }^{9}$

We do not want to claim that the model embodied in equation (1) can capture all the available Dictator game evidence. First, it seems likely that social distance between the dictator and the recipient also matters significantly. Bohnet and Frey (1999) find that dictators give more when they can see the recipient; similarly Charness and Gneezy (2008) show that gifts go up when the dictator learns the recipient's surname. Reductions in social distance may also explain why pre-play and anticipated post-play messages by the recipient serve to increase giving (Andreoni, 2011; Ellingsen and Johannesson, 2008b; Houser and Xiao, 2010; Mohlin and Johannesson, 2008). Similarly, dictators who are exposed to other dictators' decisions or to recipient expectations tend to give more on average, even for a given level of anonymity (Biccieri and Xiao, 2009; Ellingsen et al, 2010; Krupka and Weber, 2009). ${ }^{10}$ While some of these findings could be due to actual transmission of information about norms and about other people's feelings, a direct effect of social distance better fits the sum of the evidence. Nonetheless, it seems to us that "social distance" is a concept that is both more specific and tractable than "social frame," and thus represents less of a challenge for decision theory. We therefore leave it aside here.

That said, at an abstract level it is easy enough to introduce social framing effects in the above model. Simply multiply the second term by a parameter $\varphi^{F}$, denoting the congruence between the frame $F$ and the social norm. Then, the utility function becomes

$$
U_{i}=u(1-s, m)+\varphi^{F} \eta_{i} v(s-1 / 2) .
$$

For example, if the equal division norm is expected to be more salient under a Giving frame than under a Keeping frame, the distribution of gifts should move upwards in the former

\footnotetext{
${ }^{9}$ Another possibility is that the ideal point changes for some subjects, who think that the norm prescribes an equal split of whatever surplus they have the power to distribute.

${ }^{10}$ There are also several studies suggesting that subtle primes, such as pictures of eyes or a few dots arranged like a face on the computer screen, affect behavior in Dictator games (Haley and Fessler, 2005; Rigdon et al, 2009). One interpretation is that these cues subconsciously enhance concerns for social esteem or decrease the felt social distance.
} 
case. Thus, while it seems hard to develop a general model that includes social framing effects (because it requires a metric that relates frames to each other), it is straightforward to merely measure the magnitude of such an effect in an experiment where the frames, as well as other features, are tightly controlled. Indeed, as the effect is expected to be monotonic across dictator types in our experiment, we may merely compare the mean gifts under the two frames.

\section{THE FIRST STUDY}

We recruited 400 subjects from public spaces around Harvard University in June 2008 to play a one-shot Dictator game. Half of the subjects were randomly assigned to be dictators, and the other half to be recipients. Subjects were randomly allocated to one of two different rooms, which ahead of time had been randomized to the different treatments. All subjects in the same room were in the same role (dictators or recipients), and all subjects in a room were in the same treatment. All subjects were paid a show-up fee of \$5. The study took approximately 10 minutes.

In our $2 \mathrm{X} 2$ design, the game is (i) framed either in terms of giving or taking, and (ii) recipients are either uninformed or informed about the game. ${ }^{11}$ In each of the four treatments, dictators make a choice about how to divide $\$ 10$ between themselves and another anonymous subject (the recipient).

We frame the game in the following way. Every dictator receives two numbered envelopes and a set of written instructions. One of the envelopes is marked "You" and the other is marked “Other person”. In the giving game, the "You” envelope contains 10 \$1 bills and the other envelope is empty, whereas in the taking game the "You" envelope is empty while the "Other person” envelope contains 10 \$1 bills. In the instructions, subjects are informed that they will play either the "Giving game” or the "Taking game," and that they will decide how many bills to "give to" or "take from" the recipient. In both the giving game and the taking game, dictators go behind a screen one at a time, and move as much money from one envelope to the other as they wish. Once a dictator reaches a decision, he/she puts the "Other person" envelope in a box marked "Mail," and keeps the "You” envelope. Dictators then fill out a questionnaire on

\footnotetext{
${ }^{11}$ When Koch and Norman (2008) manipulate recipient awareness of the game, there is a tendency for gifts to become smaller when the recipient gets the money but is unaware of the game being played, but the effect is statistically insignificant.
} 
demographics, put it in a box marked "Questionnaire" and leave. Thus the framing is done via both the name of the game and the labeling of the allocation action.

In order to detect any role of esteem concerns, we let recipients be either uninformed or informed about the existence of a game. When uninformed, they do not know they are recipients in a Dictator game. When informed, they are given the same instructions as the dictators in their treatment. By having all recipients, uninformed and informed, fill out a questionnaire on an unrelated topic, uninformed recipients believe they are receiving money for completion of this questionnaire (note that we do not deceive the subjects, since all recipients fill out this questionnaire and we do not explicitly tell the recipients that they receive money for completion of the questionnaire). Dictators know whether their recipient is uninformed or informed, but are unaware of the existence of any of the treatments other than the one they are participating in.

When all dictators in a session had made their decisions, the experimenters took the box marked mail to another room, and recorded the content of each envelope without removing any bills from the envelope. The experimenters then took the envelopes to the room with the recipients, and distributed the money to the recipients.

\subsection{Results}

The average transfer is very similar across the four treatments (Figure 1). To test foran effect of how the game is framed (giving versus taking), for an effect of recipient information about the payoff structure (uninformed versus informed), and for an interaction between the two, we perform six regression analyses. All analyses use ordinary least squares (OLS) regression with robust standard errors, ${ }^{12}$ taking percentage transferred as the dependent variable (0 to 100 ), and including controls for gender and age (Tables 1 and 2). ${ }^{13}$

First we test the effect of the framing of the game. We begin by examining the case when the recipient is uninformed, comparing the Giving-Uninformed and Taking-Uninformed treatments. We find no significant effect of a 'Taking' dummy (coeff $=-0.51, p=0.923$ ). Next we test the effect of the framing of the game when the recipient is informed, comparing the Giving-Informed and Taking-Informed treatments. We again find no significant effect of a

\footnotetext{
${ }^{12}$ Instead using Tobit regression with robust standard errors, to account for the minimum (0) and maximum (100) transfer percentages, gives qualitatively equivalent results. We choose to report OLS results so as to have directly interpretable coefficients.

${ }^{13}$ We consistently find a significant positive effect of female gender on dictator transfer.
} 
'Taking' dummy (coeff $=-3.56, p=0.504$ ). Finally, we test the effect of framing the game while pooling over both recipient information conditions. Yet again, we find no significant effect of a 'Taking' dummy (coeff $=-3.2, \mathrm{p}=0.370$ ).

Second we test the effect of informing the recipient. We begin by examining the giving game, comparing Giving-Uninformed and Giving-Informed. We find no significant effect of an 'Informed' dummy (coeff $=6.73, p=0.211$ ). Next we test the effect of informing the recipient in the taking game, comparing Taking-Uninformed and Taking-Informed. We again find no significant effect of an 'Informed' dummy (coeff $=2.43$, p $=0.651$ ). Finally, we test the effect of informing the recipient, pooling over both frames. Yet again, we find no significant effect of an 'Informed' dummy (coeff $=4.15, \mathrm{p}=0.253$ ).

In sum, we find no significant effect of either how the game is framed or whether the recipient is informed of the payoff structure.

\section{THE SECOND STUDY}

A possible objection to the first study is that the "taking" label is ambiguous. Perhaps some subjects interpret the label as a license to take rather than a reminder of the immorality of moving money from the other's envelope? In that case, the unselfishness induced by putting money in the "other" envelope will be counteracted, rather than magnified, by the taking label.

In the second study, we therefore return to a more standard set-up. The endowment always originally belongs to the dictator, and the names of the game and the strategies are chosen to have perfectly unambiguous normative implications: The Giving Game is contrasted with the Keeping Game.

We recruited 1586 subjects from MTurk in March and April 2010 to play a modified oneshot dictator game. 793 subjects were randomly allocated to be dictators and 793 to be recipients. Subjects were randomly allocated to be either dictator or recipient in one of four different treatments. All subjects were paid a show-up fee of 20 cents. The study took on average 3 minutes to complete. ${ }^{14}$

\footnotetext{
${ }^{14}$ Online labor markets in general, and MTurk in particular, have recently received considerable attention as powerful platforms for performing incentive-compatible experiments. On MTurk, employers hire workers from around the world to complete short tasks for small amounts of money (usually less than $\$ 1$ ). This allows researchers to recruit large number of subjects quickly with little effort or expense. Stakes are generally much lower in MTurk experiments than in physical lab experiments, a feature that is partly justified by the much smaller time costs
} 
In our 2X2 design, (i) the game is framed either in terms of giving or keeping, and (ii) the action label is either neutral or active. In all four treatments, dictators receive 100 cents and choose how to allocate those 100 cents between themselves and another anonymous subject (the recipient).

We frame the game by informing subjects, in the written instructions, that they are playing either "the giving game” or "the keeping game”.

The action label is either neutral ("Transfer") or active ("Give” in the giving game and "Keep” in the keeping game). In the treatments with the neutral action label (Giving-Transfer and Keeping-Transfer) and the 'Give' action label (Giving-Give), dictators use a sliding bar to indicate the number of cents (out of 100) they want to recipient to receive. In the treatment with the 'Keep' action label (Keeping-Keep) dictators instead indicate the number of cents they want to receive themselves (again using a 0-to-100 sliding bar).

Once a dictator has made her decision, she fills out a questionnaire on demographics. To explore the effect of framing on beliefs, recipients are asked to indicate how much of 100 cents they expect to receive from their dictator. Recipients then fill out the same questionnaire. In all treatments, dictators and recipients get the same instructions about the setup.

\subsection{Results}

We begin by considering dictator transfers. As in Study 1, the average transfer is very similar across the four treatments of Study 2 (Figure 2). To test for effects of the game name (giving versus keeping) and the action label (transfer versus give/keep), we use a regression analysis similar to that of Study 1 . All analyses use ordinary least squares (OLS) regression with robust standard errors, ${ }^{15}$ taking percentage transferred as the dependent variable, and including controls for gender, age and country of residence (Tables 3 and 4).

First we test the effect of the framing of the game. We begin by examining the case when the action is labeled neutrally, comparing the Giving-Transfer and Keeping-Transfer treatments.

associated with participating. Online experiments also necessarily permit less control over subjects during the study. To address these and other concerns regarding the validity of experiments run on MTurk, a number of replication studies have been undertaken (see Rand 2011 for an overview). Most relevant for the present study, quantitative agreement between behavior on MTurk and in the physical lab has been demonstrated in a one-shot prisoners' dilemma (Horton et al., 2011) and a repeated 4-player public goods game (Suri and Watts, 2011); and it has been shown that subjects on MTurk respond to framing manipulations (Paolacci et al., 2010; Horton et al., 2011).

${ }^{15}$ As in Study 1, instead using Tobit regression gives qualitatively equivalent results. 
We find no significant effect of a 'Keeping' dummy (coeff $=0.84, \mathrm{p}=0.739$ ). Next we test the effect of the game name when the action is also given a label with valence, comparing the Giving-Give and Keeping-Keep treatments. We again find no significant effect of a 'Keeping' dummy (coeff $=-2.86, \mathrm{p}=0.696$ ). Finally, we test the effect of game name while pooling over both action labeling conditions. Yet again, we find no significant effect of a 'Keeping' dummy (coeff $=-0.67, \mathrm{p}=0.720)$.

Second we test the effect of giving the action a neutral label ("Transfer") versus an active label (“Give” or "Keep”). We begin by examining the giving game, comparing Giving-Transfer and Giving-Give. We find no significant effect of a 'Transfer' dummy (coeff = -1.41, p = 0.591). Next we test the effect of the action label in the keeping game, comparing Keeping-Transfer and Keeping-Keep. We again find no significant effect of a 'Transfer' dummy (coeff $=0.92, \mathrm{p}=0$. 738). Finally, we test the effect of neutral versus active label, pooling over both games. Yet again, we find no significant effect of a 'Transfer' dummy (coeff $=-0.90, \mathrm{p}=0.630$ ).

Thus, as in Study 1, we find no significant framing effects. Neither the name of the game nor the action label significantly changes the average transfer.

We finally turn to recipient beliefs about dictator transfers. Recipients are quite accurate in their predictions, and we find no significant difference between expected and actual transfers overall, or within each treatment (Rank-sum, $\mathrm{p}>0.10$ for all comparisons) ${ }^{16}$. Therefore, as can be seen in Figure 3, expected transfers also do not vary across treatments. We perform the same set of regressions used above to test for effects of game name and action label, and again find no significant effects (Tables 5 and 6). Thus we find no evidence that framing changed the beliefs of the recipients about how the dictators would behave.

\section{FINAL REMARKS}

As noted in the Introduction, there is a widespread concern that people's conception of situations and the norms that govern them are easily malleable - that minor changes in how the situation is described can affect people's preferences. However, our experimental evidence rejects the hypothesis that behavior in a Dictator game is sensitive to the naming of the game or

\footnotetext{
${ }^{16}$ The difference between expected and actual transfers remains non-significant when including only attentive subjects (Rank-sum, $\mathrm{p}>0.10$ for all comparisons).
} 
of the strategies. If there is such an effect at all in our experiment, we have enough statistical power to say that it is small.

After completing our work, we became aware of Suvoy (2003), an unpublished Honors thesis reporting evidence from an experiment quite similar to our first study - a dictator game framed as either a taking game or a giving game, with associated entitlements. Like us, Suvoy failed to identify any significant effect of the frame on behavior, rejecting his (and our) hypothesis that the dictator would be less greedy in the take frame. However, we think that our rejection is even stronger, since we expose each subject to one frame only; Suvoy let each subject make decisions under both frames.

Our studies are also closely related to Leliveld, van Dijk, and van Beest (2008), who investigate framing effects on proposer behavior in the Ultimatum game. They consider three frames: "giving", "splitting”, and "taking." They find that the proposals are more generous in the "taking" treatment (the opponent has the entitlement) than in the "giving" treatment in (the proposer has the entitlement). These findings are perfectly in line with our initial expectations, and the effect sizes are considerable. Why, then, is it that there is a framing effect in this study but not in ours? One reason would be that responder can reject in the Ultimatum game, and that proposers anticipate more aggressive rejections under the taking frame. However, Leliveld, van Dijk, and van Beest (2008) apparently control carefully for this effect. Another explanation is that procedures differ in the two studies. We are particularly concerned that subjects in a study conducted by psychologists are suspicious that they are being deceived or that payments are not real. (As it happens, Leliveld, van Dijk, and van Beest deceived their subjects, because they were not playing against another subject at all, and ultimate payments didn't depend on their behavior, despite instructions to the contrary.) In this case, some subjects may simply decide to neglect the monetary incentives and instead behave either according to some moral norm or as they think that the experimenters desire. A final explanation could be that Ultimatum game proposer behavior is in fact more sensitive to framing effects ("more fragile") than Dictator behavior quite contrary to the conventional wisdom.

In light of currently available evidence, our own conclusion is that preferences are less sensitive to social framing effects than we previously thought, but that considerable uncertainty remains. 


\section{REFERENCES}

Andreoni, J. (1995). "Warm-glow versus cold-prickle: The effects of positive and negative framing on cooperation in experiments,” Quarterly Journal of Economics 110(1), 1-21.

Andreoni, J. and Bernheim, B.D. (2009). "Social image and the 50-50 norm: A theoretical and experimental analysis of audience effects,” Econometrica 77, 1607-1636.

Andreoni, J. and Miller, J. (2002). “Giving according to GARP: An experimental test of the consistency of preferences for altruism,” Econometrica 70, 737-753.

Andreoni, J. and Rao, J. (2011). “The power of asking: How communication affects selfishness, empathy, and altruism,” Journal of Public Economics 95, 513-520.

Bacharach, M. (1993). “Variable universe games,” in K. Binmore, A. Kirmanand, and P. Tani (eds.), Frontiers of Game Theory, 255-276, Cambridge MA: MIT Press.

Bacharach, M. (1999). "Interactive team reasoning: A contribution to the theory of cooperation,” Research in Economics 53, 117-147.

Bardsley, N. (2008). “Dictator game giving: Altruism or artifact,” Experimental Economics11, 122-133.

Batson, C.D. and Moran, T. (1999). “Empathy-induced altruism in a prisoner's dilemma,” European Journal of Social Psychology 29, 909-924.

Becker, G.S. (1974). “A theory of social interactions,” Journal of Political Economy 82, 10631093.

Becker, G.S. and Stigler, G.J. (1977). “De gustibus non est disputandum,” American Economic Review Papers and Proceedings 67, 76-90.

Bicchieri, C. and Xiao, E. (2009). "Do the right thing: But only if others do so," Journal of Behavioral Decision Making 22, 191-208.

Bohnet, I. and Frey, B. (1999). “Social distance and other-regarding behavior: Comment,” American Economic Review 89, 335-340.

Brandts, J. and Schwieren, C. (2009). "Frames and economic behavior: An experimental study,” manuscript, Universitat Autònoma de Barcelona. 
Brewer, M.B. and Kramer, R.M. (1986). “Choice behavior in social dilemmas: Effects of social identity, group size, and decision framing,” Journal of Personality and Social Psychology, 50(3), 543-549.

Broberg, T., Ellingsen, T., and Johannesson, M. (2007). “Is generosity involuntary?” Economics Letters 94, 32-37.

Camerer, C.F. (2003). Behavioral Game Theory: Experiments in Strategic Interaction. New Jersey: Princeton University Press.

Cappelen, A., Hole, A.D., Sørensen, E.Ø., and Tungodden, B. (2007). “The pluralism of fairness ideals: An experimental approach,” American Economic Review 97, 818-827.

Charness, G. and Gneezy, U. (2008). "What's in a name? Anonymity and social distance in dictator and ultimatum games,” Journal of Economic Behavior and Organization 68, 29-35.

Cherry, T.L., Frykblom, P., and Shogren, J.F. (2002). “Hardnose the dictator,”American Economic Review 92, 1218-1221.

Cookson, R. (2000). "Framing effects in public goods experiments,” Experimental Economics 3, 55-79.

Cubitt, R.P., Drouvelis, M., and Gächter, S. (2011). "Framing and free riding: Emotional responses and punishment in social dilemma games,” Experimental Economics 14, 254-272.

Dana, J., Cain, D.M., and Dawes, R.M. (2006). “What you don’t know won’t hurt me: Costly but quiet exit in dictator games,” Organizational Behavior and Human Decision Processes 100, 193201.

Deutsch, M. (1958). “Trust and suspicion,” Journal of Conflict Resolution 2, 265-279.

Deutsch, M. (1960). “The effect of motivational disposition on trust and suspicion,” Human Relations 13, 123-139.

Dufwenberg, M., Gächter, S., and Hennig-Schmidt, H. (2011). “The framing of games and the psychology of play,” Games and Economic Behavior, forthcoming.

Eiser, J.R. and Bhavnani, K. (1974). “The effect of situational meaning on the behaviour of subjects in the Prisoner's Dilemma Game,” European Journal of Social Psychology 4(1), 93-97. 
Ellingsen, T. and Johannesson, M. (2008b). “Anticipated verbal feedback induces altruistic behavior,” Evolution and Human Behavior 29, 100-105.

Ellingsen, T., Johannesson, M., Mollerstrom, J., and Munkhammar, S. (2011). "Social framing effects: Preferences or beliefs?” Manuscript, Stockholm School of Economics.

Ellingsen, T., Johannesson, M., Torsvik, G., and Tjøtta, S. (2011). "Testing guilt aversion,” Games and Economic Behavior 68, 95-107.

Engel, C. (2011). “Dictator games: A meta study,” Experimental Economics 14, forthcoming.

Fehr, E. and Schmidt, K. (2006). "The economics of fairness, reciprocity and altruism - experimental evidence and new theories," in S.-C. Kolm and J.M. Ythier (eds.): Handbook of the Economics of Giving, Altruism and Reciprocity, volume 1. Amsterdam: Elsevier.

Haley, Kevin J. and Fessler, D.M.T.(2005). "Nobody’s watching? Subtle cues affect generosity in an anonymous economic game.” Evolution and Human Behavior 26, 245-56.

Hoffman, E., McCabe, K.A., Shachat, K., and Smith, V.L.(1994). "Preferences, Property Rights, and Anonymity in Bargaining Games,” Games and Economic Behavior 7, 346-80.

Horton, J.J., Rand, D.G., and Zeckhauser, R.J. (2011). “The online laboratory: Conducting experiments in a real labor market,” Experimental Economics 14, 399-425.

Houser, D. and Xiao, E. (2009). "Avoiding the sharp tongue: Anticipated written messages promote fair economic exchange,” Journal of Economic Psychology 30, 393-404.

Kay, A.C. and Ross, L. (2003). "The perceptual push: The interplay of implicit cues and explicit situational construals on behavioral intentions in the Prisoner's dilemma," Journal of Experimental Social Psychology 39, 634-643.

Keysar, B., Converse, B.A., Wang, J., and Epley, N. (2008). "Reciprocity is not give and take: Asymmetric reciprocity to positive and negative acts," Psychological Science 19(12), 12801286.

Koch, A. and Norman, H.-T. (2008). "Giving in dictator games: Regard for others or regard by others?” Southern Economic Journal 75, 223-231.

Konow, J. (2010). "Mixed feelings: Theories and evidence on giving," Journal of Public Economics 94, 279-297. 
Krupka, E. and Weber, R.A. (2009). “The focusing and informational effects of norms on prosocial behavior,” The Journal of Economic Psychology 30, 307-320.

Krupka, E. and Weber, R.A. (2010). "Identifying social norms using coordination games: Why does dictator game sharing vary?” Manuscript, Carnegie Mellon University.

Lazear, E.P., Malmendier, U., and Weber, R.A. (2010). “Sorting, prices, and social preferences,” Manuscript, University of California, Berkeley.

Leliveld, M.C., van Dijk, E., and van Beest, I. (2008). “Ownership in bargaining: Introducing the giving, splitting, and taking ultimatum bargaining game,” Personality and Social Psychology Bulletin 34(9), 1214-1225.

Levin, I.P., Schneider, S.L., and Gaeth, G.J. (1998). “All frames are not created equal: A typology and critical analysis of framing effects," Organizational Behavior and Human Decision Processes 76(2), 149-188.

Levitt, S. and List, J. (2007). "What do laboratory experiments measuring social preferences reveal about the real world?” Journal of Economic Perspectives 21(2), 151-174.

Liberman, V., Samuels, S.M., and Ross, L. (2004). "The name of the game: Predictive power of reputations versus situational labels in determining Prisoner's Dilemma game moves,” Personality and Social Psychology Bulletin 30(9), 1175-1185.

March, J. (1994). A Primer on Decision-Making: How Decisions Happen. New York: Free Press. McCusker, C., \& Carnevale, P.J. (1995). “Framing in resource dilemmas: Loss aversion and the moderating effects on sanctions," Organizational Behavior and Human Decision Processes 61, 190-201.

McDaniel, W.C., \& Sistrunk, F. (1991). "Management dilemmas and decisions: impact of framing and anticipated responses,” Journal of Conflict Resolution 35, 21-42.

Mohlin, E. and Johannesson, M. (2008). ”Communication: Content or relationship?” Journal of Economic Behavior and Organization 65, 409-419.

Montgomery, J.D. (1998). “Toward a role-theoretic conception of embeddedness,” American Journal of Sociology 104(1), 92-125.

Paolacci, G., Chandler, J., and Ipeirotis, P.G. (2010). “Running experiments on Amazon 
Mechanical Turk,” Judgment and Decision Making 5, 411-419.

Pillutla, M.M. and Chen, X. (1999). "Social norms and cooperation in social dilemmas: The effects of context and feedback," Organizational Behavior and Human Decision Processes 78(2), 81-103.

Rabin, M. (1998). “Psychology and economics,” Journal of Economic Literature 36 (1), 11-46.

Rand, D.G. (2011) “The promise of Mechanical Turk: How online labor markets can help theorists run behavioral experiments,” Journal of Theoretical Biology DOI:10.1016/j.jtbi.2011.03.004

Rege, M. and Telle, K. (2004). "The impact of social approval and framing on cooperation in public good situations,” Journal of Public Economics 88, 1625-1644.

Rigdon, M., Ishii, K., Watabe, M., and Kitayama, S. (2009). "Minimal social cues in the dictator game,” Journal of Economic Psychology 30, 358-367.

Salant, Y. and Rubinstein, A. (2008). “(A,f): Choice with frames,” Review of Economic Studies, 75, 1287-1296.

Sell, J., and Son, Y. (1997). "Comparing public goods and common pool resources: three experiments," Social Psychology Quarterly 60, 118-137.

Sobel, J. (2005). “Interdependent preferences and reciprocity,” Journal of Economic Literature 43, 392-436.

Sonnemans, J., Schram, A., and Offerman, T. (1998). "Public good provision and public bad prevention: The effect of framing,” Journal of Economic Behavior and Organization 34, 143 161.

Sugden, R. (1993). "Thinking as a team: Towards an explanation of nonselfish behavior, Social Philosophy and Policy 10, 69-89.

Suri, S., and Watts, D.J. (2011). "Cooperation and contagion in networked public goods experiments,"PLoS ONE 6, e16836. 
Suvoy, R. (2003). “The effects of give and take framing in a dictator game,” Unpublished Honors Thesis, University of Oregon.

Tadelis, S. (2008). "The power of shame and the rationality of trust,” manuscript, University of California, Berkeley, Haas School of Business.

Tversky, A. and Kahneman, D. (1981). "The framing of decisions and the psychology of choice,” Science 211, 453-458.

van Dijk, E. and Wilke, H. (2000). "Decision-induced focusing in social dilemmas: Give-some, keep-some, take-some, and leave-some dilemmas," Journal of Personality and Social Psychology 78(1), 92-104.

Weber, J.M. et al. (2004). "A conceptual review of decision making in social dilemmas: Applying a logic of appropriateness,” Personality and Social Psychology Review 8(3), 281-307.

Zhong, C.-B., Loewenstein, J., and Murnighan, J.K. (2007). “Speaking the same language: The cooperative effects of $\mu$ in the Prisoners' Dilemma," Journal of Conflict Resolution 51(3), 431456. 


\section{Figures}

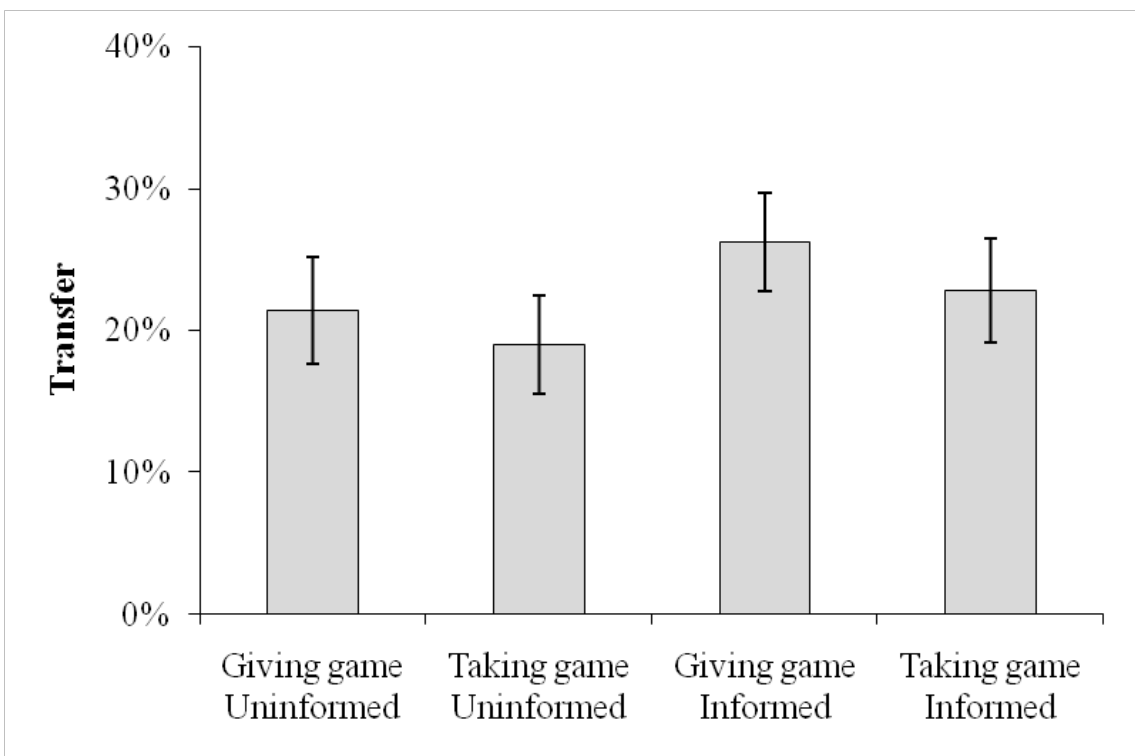

Figure 1. Average dictator game transfer in Study 1 (out of \$10), by framing of the game (giving versus taking) and recipient information (uninformed versus informed). 


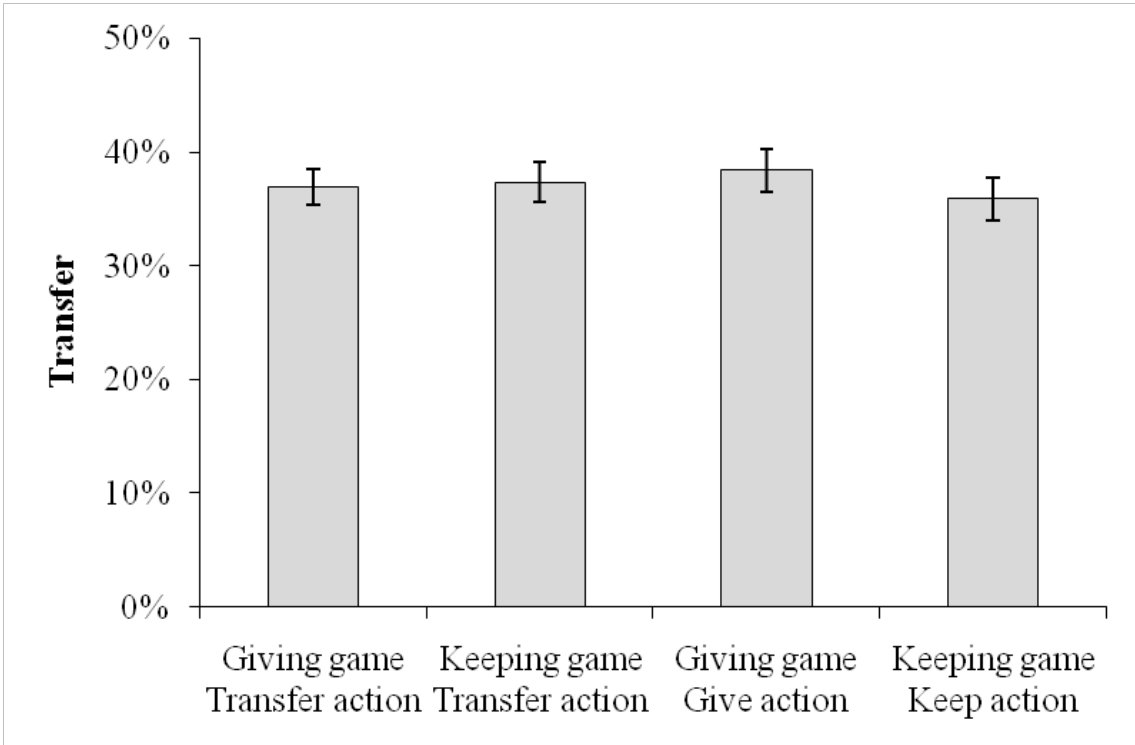

Figure 2. Average dictator game transfer (out of 100 cents) in Study 2, by framing of the game (giving versus keeping) and labeling of the action (transfer versus give/keep). 


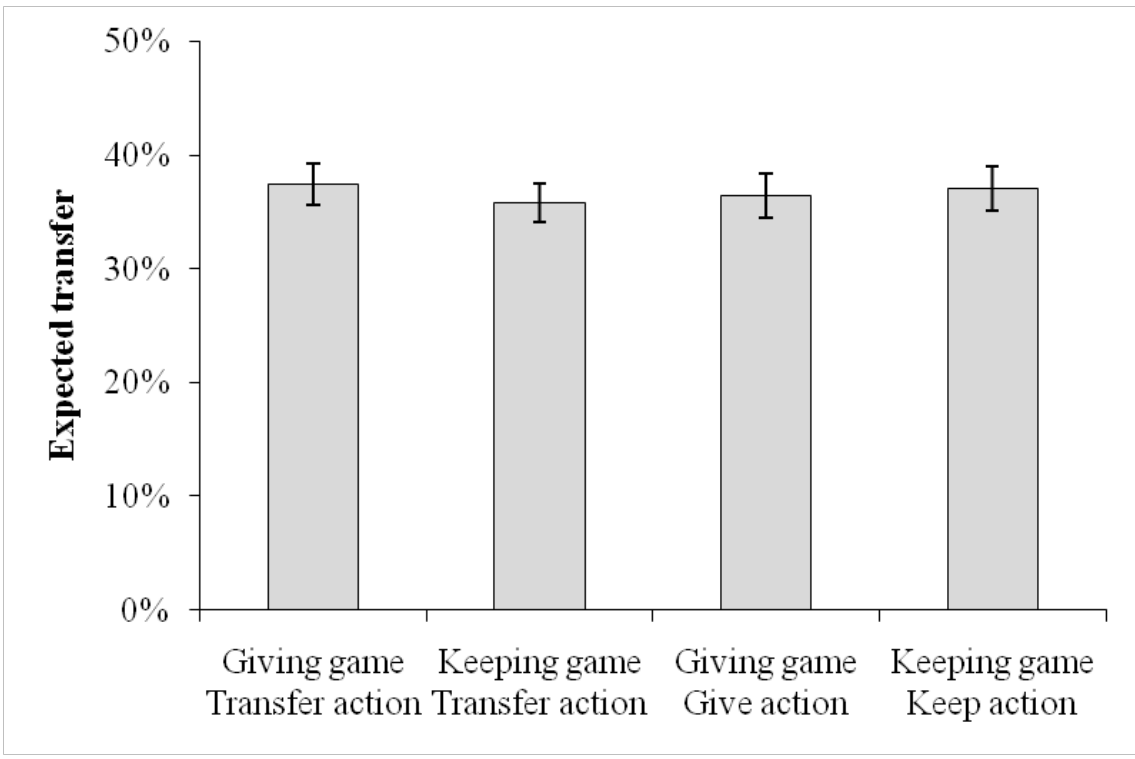

Figure 3.Average dictator game transfer expected by recipients (out of 100 cents) in Study 2, by framing of the game (giving versus keeping) and labeling of the action (transfer versus give/keep). 
Tables

\begin{tabular}{|c|c|c|c|c|c|c|}
\hline \multirow[b]{2}{*}{ Taking Game } & \multicolumn{2}{|c|}{$\begin{array}{l}\text { Giving-Uninformed \& } \\
\text { Taking-Uninformed }\end{array}$} & \multicolumn{2}{|c|}{$\begin{array}{c}\text { Giving-Informed \& } \\
\text { Taking-Informed }\end{array}$} & \multicolumn{2}{|c|}{ All data } \\
\hline & $\begin{array}{l}-2.400 \\
(5.129)\end{array}$ & $\begin{array}{l}-0.506 \\
(5.243)\end{array}$ & $\begin{array}{l}-3.400 \\
(5.046)\end{array}$ & $\begin{array}{l}-3.556 \\
(5.297)\end{array}$ & $\begin{array}{l}-2.900 \\
(3.593)\end{array}$ & $\begin{array}{l}-3.189 \\
(3.545)\end{array}$ \\
\hline Female & & $\begin{array}{l}14.09 * * * \\
(5.337)\end{array}$ & & $\begin{array}{l}1.940 \\
(5.255)\end{array}$ & & $\begin{array}{l}7.878 * * \\
(3.723)\end{array}$ \\
\hline Age & & $\begin{array}{l}-0.0280 \\
(0.268)\end{array}$ & & $\begin{array}{l}-0.140 \\
(0.401)\end{array}$ & & $\begin{array}{l}-0.0921 \\
(0.228)\end{array}$ \\
\hline Constant & $\begin{array}{l}21.40 * * * \\
(3.780)\end{array}$ & $\begin{array}{l}14.46 * \\
(7.786)\end{array}$ & $\begin{array}{l}22.80 * * * \\
(3.704)\end{array}$ & $\begin{array}{l}=24.80 * * \\
(9.708)\end{array}$ & $\begin{array}{l}20.90 * * * \\
(2.531)\end{array}$ & $\begin{array}{l}19.04 * * * \\
(5.324)\end{array}$ \\
\hline Observations & 100 & 100 & 100 & 100 & 200 & 200 \\
\hline R-squared & 0.002 & 0.077 & 0.005 & 0.008 & 0.003 & 0.027 \\
\hline
\end{tabular}

Table 1: The effect of game name on transfers in Study 1

\begin{tabular}{|c|c|c|c|c|c|c|}
\hline \multirow[b]{2}{*}{ Informed Recipient } & \multicolumn{2}{|c|}{$\begin{array}{c}\text { Giving-Uninformed \& } \\
\text { Giving-Informed }\end{array}$} & \multicolumn{2}{|c|}{$\begin{array}{l}\text { Taking-Uninformed } \\
\text { \& Taking-Informed }\end{array}$} & \multicolumn{2}{|c|}{ All data } \\
\hline & $\begin{array}{l}4.800 \\
(5.102)\end{array}$ & $\begin{array}{l}6.729 \\
(5.349)\end{array}$ & $\begin{array}{l}3.800 \\
(5.073)\end{array}$ & $\begin{array}{l}2.432 \\
(5.358)\end{array}$ & $\begin{array}{l}4.300 \\
(3.585)\end{array}$ & $\begin{array}{l}4.152 \\
(3.623)\end{array}$ \\
\hline Female & & $\begin{array}{l}5.786 \\
(5.216)\end{array}$ & & $\begin{array}{l}10.55^{*} \\
(5.391)\end{array}$ & & $\begin{array}{l}7.684 * * \\
(3.743)\end{array}$ \\
\hline Age & & $\begin{array}{l}0.308 \\
(0.338)\end{array}$ & & $\begin{array}{l}-0.442 * * \\
(0.180)\end{array}$ & & $\begin{array}{l}-0.0691 \\
(0.242)\end{array}$ \\
\hline Constant & $\begin{array}{l}21.40 * * * \\
(3.780)\end{array}$ & $\begin{array}{l}10.91 \\
(8.758)\end{array}$ & $\begin{array}{l}22.80 * * * \\
(3.704)\end{array}$ & $\begin{array}{l}26.55 * * * \\
(6.759)\end{array}$ & $\begin{array}{l}24.50 * * * \\
(2.516)\end{array}$ & $\begin{array}{l}22.30 * * * \\
(5.288)\end{array}$ \\
\hline Observations & 100 & 100 & 100 & 100 & 200 & 200 \\
\hline R-squared & 0.009 & 0.034 & 0.006 & 0.061 & 0.007 & 0.030 \\
\hline
\end{tabular}

Table 2: The effect of recipient information on transfers in Study 1 


\begin{tabular}{|c|c|c|c|c|c|c|}
\hline \multirow[b]{2}{*}{ Keeping Game } & \multicolumn{2}{|c|}{$\begin{array}{l}\text { Giving-Transfer \& } \\
\text { Keeping-Transfer }\end{array}$} & \multicolumn{2}{|c|}{$\begin{array}{l}\text { Giving-Give \& } \\
\text { Keeping-Keep }\end{array}$} & \multicolumn{2}{|c|}{ All data } \\
\hline & $\begin{array}{l}0.451 \\
(2.341)\end{array}$ & $\begin{array}{l}0.839 \\
(2.519)\end{array}$ & $\begin{array}{l}-2.52 \\
(2.648)\end{array}$ & $\begin{array}{l}-1.118 \\
(2.862)\end{array}$ & $\begin{array}{l}-0.912 \\
(1.752)\end{array}$ & $\begin{array}{l}-0.668 \\
(1.863)\end{array}$ \\
\hline Gender & & $\begin{array}{l}-0.807 \\
(2.677)\end{array}$ & & $\begin{array}{l}-0.627 \\
(3.088)\end{array}$ & & $\begin{array}{l}-0.860 \\
(1.998)\end{array}$ \\
\hline Age & & $\begin{array}{l}-0.0492 \\
(0.126)\end{array}$ & & $\begin{array}{l}0.154 \\
(0.135)\end{array}$ & & $\begin{array}{l}0.0464 \\
(0.0905)\end{array}$ \\
\hline Constant & $\begin{array}{l}36.89 * * * \\
(1.565)\end{array}$ & $\begin{array}{l}2.362 \\
(6.045)\end{array}$ & $\begin{array}{l}35.90 * * * \\
(1.871)\end{array}$ & $\begin{array}{l}29.29 * * * \\
(5.010)\end{array}$ & $\begin{array}{l}36.62 * * * \\
(1.276)\end{array}$ & $\begin{array}{l}97.33^{* * *} \\
(4.369)\end{array}$ \\
\hline $\begin{array}{l}\text { Country of residence } \\
\text { dummies }\end{array}$ & No & Yes & No & Yes & No & Yes \\
\hline $\begin{array}{l}\text { Observations } \\
\text { R-squared }\end{array}$ & $\begin{array}{l}430 \\
0.000\end{array}$ & $\begin{array}{l}429 \\
0.133\end{array}$ & $\begin{array}{l}363 \\
0.003\end{array}$ & $\begin{array}{l}361 \\
0.083\end{array}$ & $\begin{array}{l}793 \\
0.000\end{array}$ & $\begin{array}{l}790 \\
0.085\end{array}$ \\
\hline $\begin{array}{l}\text { Robust standard error } \\
* * * \mathrm{p}<0.01, * * \mathrm{p}<0.0\end{array}$ & s in parent & & & & & \\
\hline
\end{tabular}

Table 3: The effect of game name in Study 2

\begin{tabular}{|c|c|c|c|c|c|c|}
\hline \multirow[b]{2}{*}{ Transfer Action } & \multicolumn{2}{|c|}{$\begin{array}{l}\text { Giving-Transfer \& } \\
\text { Giving-Give }\end{array}$} & \multicolumn{2}{|c|}{$\begin{array}{l}\text { Keeping-Transfer \& } \\
\text { Keeping-Keep }\end{array}$} & \multicolumn{2}{|c|}{ All data } \\
\hline & $\begin{array}{l}-1.53 \\
(2.441)\end{array}$ & $\begin{array}{l}-1.408 \\
(2.615)\end{array}$ & $\begin{array}{l}.441 \\
(2.556)\end{array}$ & $\begin{array}{l}-0.924 \\
(2.758)\end{array}$ & $\begin{array}{l}-0.0407 \\
(1.762)\end{array}$ & $\begin{array}{l}-0.900 \\
(1.866)\end{array}$ \\
\hline Gender & & $\begin{array}{l}-2.223 \\
(2.738)\end{array}$ & & $\begin{array}{l}1.384 \\
(2.953)\end{array}$ & & $\begin{array}{l}-0.916 \\
(1.998)\end{array}$ \\
\hline Age & & $\begin{array}{l}0.200 \\
(0.130)\end{array}$ & & $\begin{array}{l}-0.0544 \\
(0.128)\end{array}$ & & $\begin{array}{l}0.0448 \\
(0.0904)\end{array}$ \\
\hline Constant & $\begin{array}{l}36.89 * * * \\
(1.565)\end{array}$ & $\begin{array}{l}91.38 * * * \\
(5.590)\end{array}$ & $\begin{array}{l}35.90 * * * \\
(1.871)\end{array}$ & $\begin{array}{l}52.04 * * * \\
(6.766)\end{array}$ & $\begin{array}{l}37.13^{* * * *} \\
(1.324)\end{array}$ & $\begin{array}{l}98.97 * * * \\
(4.243)\end{array}$ \\
\hline $\begin{array}{l}\text { Country of } \\
\text { residence } \\
\text { dummies }\end{array}$ & No & Yes & No & Yes & No & Yes \\
\hline $\begin{array}{l}\text { Observations } \\
\text { R-squared }\end{array}$ & $\begin{array}{l}418 \\
0.001\end{array}$ & $\begin{array}{l}416 \\
0.129\end{array}$ & \begin{tabular}{|l}
375 \\
0.001
\end{tabular} & $\begin{array}{l}374 \\
0.132\end{array}$ & $\begin{array}{l}793 \\
0.000\end{array}$ & $\begin{array}{l}790 \\
0.085\end{array}$ \\
\hline
\end{tabular}

Table 4: The effect of action label in Study 2 


\begin{tabular}{|c|c|c|c|c|c|c|}
\hline \multirow[b]{2}{*}{ Keeping Game } & \multicolumn{2}{|c|}{$\begin{array}{l}\text { Giving-Transfer \& } \\
\text { Keeping-Transfer }\end{array}$} & \multicolumn{2}{|c|}{$\begin{array}{l}\text { Giving-Give \& } \\
\text { Keeping-Keep }\end{array}$} & \multicolumn{2}{|c|}{ All data } \\
\hline & $\begin{array}{l}-1.613 \\
(2.491)\end{array}$ & $\begin{array}{c}0.124 \\
(2.505)\end{array}$ & $\begin{array}{c}0.669 \\
(2.745)\end{array}$ & $\begin{array}{c}1.445 \\
(2.875)\end{array}$ & $\begin{array}{l}-0.497 \\
(1.848)\end{array}$ & $\begin{array}{c}0.442 \\
(1.841)\end{array}$ \\
\hline Gender & & $\begin{array}{c}2.583 \\
(2.694)\end{array}$ & & $\begin{array}{l}-5.187 * \\
(3.019)\end{array}$ & & $\begin{array}{l}-1.021 \\
(1.947)\end{array}$ \\
\hline Age & & $\begin{array}{c}-0.00598 \\
(0.104)\end{array}$ & & $\begin{array}{l}0.0869 \\
(0.143)\end{array}$ & & $\begin{array}{c}0.0392 \\
(0.0834)\end{array}$ \\
\hline Constant & $\begin{array}{c}37.39 * * * \\
(1.812)\end{array}$ & $\begin{array}{c}27.76 * * * \\
(6.314)\end{array}$ & $\begin{array}{c}37.08 * * * \\
(1.954)\end{array}$ & $\begin{array}{c}44.40 * * * \\
(8.596)\end{array}$ & $\begin{array}{c}36.42 * * * \\
(1.294)\end{array}$ & $\begin{array}{c}46.17 * * * \\
(5.123)\end{array}$ \\
\hline $\begin{array}{l}\text { Country of residence } \\
\text { dummies }\end{array}$ & No & Yes & No & Yes & No & Yes \\
\hline Observations & 409 & 409 & 390 & 390 & 799 & 799 \\
\hline R-squared & 0.001 & 0.194 & 0.000 & 0.168 & 0.000 & 0.159 \\
\hline
\end{tabular}

Table 5: The effect of game name on recipient's expected transfer

\begin{tabular}{|c|c|c|c|c|c|c|}
\hline \multirow[b]{2}{*}{ Transfer Action } & \multicolumn{2}{|c|}{$\begin{array}{l}\text { Giving-Transfer \& } \\
\text { Giving-Give }\end{array}$} & \multicolumn{2}{|c|}{$\begin{array}{c}\text { Keeping-Transfer \& } \\
\text { Keeping-Keep }\end{array}$} & \multicolumn{2}{|c|}{ All data } \\
\hline & $\begin{array}{c}0.987 \\
(2.646)\end{array}$ & $\begin{array}{c}0.467 \\
(2.784)\end{array}$ & $\begin{array}{l}-1.295 \\
(2.596)\end{array}$ & $\begin{array}{l}-0.524 \\
(2.579)\end{array}$ & $\begin{array}{l}-0.142 \\
(1.852)\end{array}$ & $\begin{array}{l}-0.741 \\
(1.834)\end{array}$ \\
\hline Gender & & $\begin{array}{l}-0.365 \\
(2.870)\end{array}$ & & $\begin{array}{l}-2.268 \\
(2.913)\end{array}$ & & $\begin{array}{l}-1.043 \\
(1.946)\end{array}$ \\
\hline Age & & $\begin{array}{l}0.0909 \\
(0.147)\end{array}$ & & $\begin{array}{c}0.115 \\
(0.122)\end{array}$ & & $\begin{array}{c}0.0398 \\
(0.0835)\end{array}$ \\
\hline Constant & $\begin{array}{c}37.39 * * * \\
(1.812)\end{array}$ & $\begin{array}{l}43.20 * * * \\
(8.924)\end{array}$ & $\begin{array}{c}37.08 * * * \\
(1.954)\end{array}$ & $\begin{array}{c}5.273 \\
(4.467)\end{array}$ & $\begin{array}{l}36.74 * * * \\
(1.371)\end{array}$ & $\begin{array}{c}45.69 * * * \\
(4.845)\end{array}$ \\
\hline $\begin{array}{l}\text { Country of } \\
\text { residence dummies }\end{array}$ & No & Yes & No & Yes & No & Yes \\
\hline Observations & 402 & 402 & 397 & 397 & 799 & 799 \\
\hline R-squared & 0.000 & 0.144 & 0.001 & 0.217 & 0.000 & 0.160 \\
\hline
\end{tabular}

Table 6: The effect of action label on recipient's expected transfer 


\section{Appendix A - Framing in a one-shot Prisoners' Dilemma on MTurk}

To demonstrate the presence of framing effects on MTurk in games where both subjects make a decision, we recruited 400 subjects from MTurk in February 2011 to play a modified one-shot Prisoners' dilemma game. Subjects were randomly allocated to one of two framing treatments. All subjects were paid a show-up fee of 25 cents. The study took on average 4 minutes to complete.

Subjects were informed that they were playing either the 'Community game' or the 'Profit game'. ${ }^{17}$ Then they read identical instructions for the following Prisoners' dilemma, indicated their decision (A or B), and completed a post-experimental questionnaire.

A
A $\$ 0.15, \$ 0.15$
B $\$ 0.20, \$ 0$
$\$ 0, \$ 0.20$
$\$ 0.05, \$ 0.05$

B

Unlike in our Dictator game experiments, we do find substantial variation in Prisoners' dilemma cooperation across treatments (Community game: 65\% cooperation, Profit game: 58\% cooperation). To test for effects of the game name, we use logistic regression with robust standard errors, taking decision to cooperate (i.e. choose option 'A') as the dependent variable, and including controls for gender, age and country of residence. We find a negative effect of the 'Profit game' frame on cooperation (coeff $=-0.446, \mathrm{p}=0.043$; Table A1).

Thus we show that framing effects do occur on MTurk in games where both players make a decision. This supports our conclusion that the lack of framing effects in our Dictator games is the result of the unilateral nature of the dictator game decision setting.

\footnotetext{
${ }^{17}$ It has been previously demonstrated in the traditional (offline) laboratory that subjects cooperation more when the PD is called the 'Community game' relative to the 'Wall Street game' (Liberman et al. 2004). In this replication, we used the term 'Profit game' instead of 'Wall Street game' because of the particular negative valence attached to Wall Street in the mind of (at least) the American public at the time of the experiment.
} 


\begin{tabular}{|c|c|c|}
\hline \multirow[b]{2}{*}{ Profit Game } & \multicolumn{2}{|c|}{$\begin{array}{c}\text { Community game vs } \\
\text { Profit game }\end{array}$} \\
\hline & $\begin{array}{l}-0.306 \\
(0.207)\end{array}$ & $\begin{array}{l}-0.446 * * \\
(0.221)\end{array}$ \\
\hline Age & & $\begin{array}{l}0.00844 \\
(0.00986)\end{array}$ \\
\hline Female & & $\begin{array}{l}0.327 \\
(0.226)\end{array}$ \\
\hline Constant & $\mid \begin{array}{l}0.626 * * * \\
0.149)\end{array}$ & $\begin{array}{l}-18.53^{* * *} \\
(1.403)\end{array}$ \\
\hline $\begin{array}{l}\text { Country of residence } \\
\text { dummies }\end{array}$ & No & Yes \\
\hline Observations & 400 & 378 \\
\hline
\end{tabular}

Table A1. The effect of game name in a Prisoner's dilemma 


\section{Appendix B: Instructions for Study 1}

GIVING GAME: INSTRUCTIONS ("baseline”; the same instructions in room A and B)

Thank you for participating in this study. You have all received a \$5 show-up fee. You also have the opportunity to receive additional money as described below.

Each of you will be paired with another person in another room based on your pair number. You will never know who this other person is, and they will never know who you are.

You are in room A (B). Every person in room A and room B has received these same instructions.

In this study we will play the giving game.

The giving game works as follows. Every person in room A has been given two numbered envelopes together with these instructions (the number is written on the inside of the envelope, and is therefore invisible to others). One of these envelopes is marked "You" and contains ten \$1 bills. The other envelope is marked "Other person" and is empty.

The experimenter asks one person at a time in room A to go behind a screen where no one else can see what happens.

Behind the screen, the person decides how many bills, if any, to give to the person in room B and puts these bills in the envelope marked "Other person". The person in room A then pockets the envelope marked "You".

When the person behind the screen has made his/her decision he/she puts the envelope marked "Other person" in the box marked "Mail". The person then proceeds to a second screen and anonymously fills out a questionnaire about the experiment. The person puts the completed questionnaire in the box marked "Questionnaire" and leaves the room. That person is now finished with the study.

When all the people in Room A have made their decisions, the experimenter takes the box marked "Mail" to an adjacent room. The experimenter records the content of each envelope, without removing any bills from the envelopes.

The experimenter then takes the envelopes to Room B, where the people have been filling out a questionnaire while they have been waiting for the envelopes to arrive. The experimenter distributes the envelopes to the people in room B according to the pair numbers on their instructions. The people in room $\mathrm{B}$ then leave their room and the study is over. 
TAKING GAME: INSTRUCTIONS ("baseline”; the same instructions in room A and B)

Thank you for participating in this study. You have all received a \$5 show-up fee. You also have the opportunity to receive additional money as described below.

Each of you will be paired with another person in another room based on your pair number. You will never know who this other person is, and they will never know who you are.

You are in room A (B). Every person in room A and room B has received these same instructions.

In this study we will play the taking game.

The taking game works as follows. Every person in room A has been given two numbered envelopes together with these instructions (the number is written on the inside of the envelope, and is therefore invisible to others). One of these envelopes is marked "Other person" and contains ten $\$ 1$ bills. The other envelope is marked "You" and is empty.

The experimenter asks one person at a time in room A to go behind a screen where no one else can see what happens.

Behind the screen, the person decides how many bills, if any, to take from the person in room B and puts these bills in the envelope marked "You". The person in room A then pockets the envelope marked "You".

When the person behind the screen has made his/her decision he/she puts the envelope marked "Other person" in the box marked "Mail". The person then proceeds to a second screen and anonymously fills out a questionnaire about the experiment. The person puts the completed questionnaire in the box marked "Questionnaire" and leaves the room. That person is now finished with the study.

When all the people in Room A have made their decisions, the experimenter takes the box marked "Mail" to an adjacent room. The experimenter records the content of each envelope, without removing any bills from the envelopes.

The experimenter then takes the envelopes to Room B, where the people have been filling out a questionnaire while they have been waiting for the envelopes to arrive. The experimenter distributes the envelopes to the people in room B according to the pair numbers on their instructions. The people in room $\mathrm{B}$ then leave their room and the study is over. 


\section{GIVING GAME: INSTRUCTIONS (“no information”; room A)}

Thank you for participating in this study. You have all received a \$5 show-up fee. You also have the opportunity to receive additional money as described below.

Each of you will be paired with another person in another room based on your pair number. You will never know who this other person is, and they will never know who you are.

You are in room A. The people in room B have NOT received these same instructions. A copy of the instructions they have received is attached.

In this study we will play the giving game.

The giving game works as follows. Every person in room A has been given two numbered envelopes together with these instructions (the number is written on the inside of the envelope, and is therefore invisible to others). One of these envelopes is marked "You" and contains ten \$1 bills. The other envelope is marked "Other person" and is empty.

The experimenter asks one person at a time in room A to go behind a screen where no one else can see what happens.

Behind the screen, the person decides how many bills, if any, to give to the person in room B and puts these bills in the envelope marked "Other person". The person in room A then pockets the envelope marked "You".

When the person behind the screen has made his/her decision he/she puts the envelope marked "Other person" in the box marked "Mail". The person then proceeds to a second screen and anonymously fills out a questionnaire about the experiment. The person puts the completed questionnaire in the box marked "Questionnaire" and leaves the room. That person is now finished with the study.

In the meantime the people in the other room (room B) have been filling out a questionnaire. They do not know anything about these study instructions or that they have been paired with another person in another room, and they will not be told at any point during or after the study.

You have been given a copy of the study instructions given to the people in room B (attached).

When all the people in Room A have made their decisions, the experimenter takes the box marked "Mail" to an adjacent room. The experimenter records the contents of each envelope and adds the \$5 dollar participation fee for the person in room B.

The experimenter then takes the envelopes to Room B. The experimenter distributes the envelopes to the people in room B according to the pair numbers on their instructions. The people in room B then leave their room and the study is over. 
INSTRUCTIONS (“no information giving game/taking game”; room B)

Thank you for participating in this study in which you will fill out a questionnaire.

For your participation you will receive a payment of $\$ 5$. After completing the questionnaire you may also receive some additional payment above and beyond the $\$ 5$ participation fee.

Both the questionnaire and these instructions are marked with your subject number.

The questionnaires will be collected after 15 minutes. You will then receive an envelope with your payment for the study.

The study is then over and you can leave the room. 
TAKING GAME: INSTRUCTIONS (“no information”; room A)

Thank you for participating in this study. You have all received a \$5 show-up fee. You also have the opportunity to receive additional money as described below.

Each of you will be paired with another person in another room based on your pair number. You will never know who this other person is, and they will never know who you are.

You are in room A. The people in room B have NOT received these same instructions. A copy of the instructions they have received is attached.

In this study we will play the taking game.

The taking game works as follows. Every person in room A has been given two numbered envelopes together with these instructions (the number is written on the inside of the envelope, and is therefore invisible to others). One of these envelopes is marked "Other person" and contains ten $\$ 1$ bills. The other envelope is marked "You" and is empty.

The experimenter asks one person at a time in room A to go behind a screen where no one else can see what happens.

Behind the screen, the person decides how many bills, if any, to take from the person in room B and puts these bills in the envelope marked "Other person". The person in room A then pockets the envelope marked "You".

When the person behind the screen has made his/her decision he/she puts the envelope marked "Other person" in the box marked "Mail". The person then proceeds to a second screen and anonymously fills out a questionnaire about the experiment. The person puts the completed questionnaire in the box marked "Questionnaire" and leaves the room. That person is now finished with the study.

In the meantime the people in the other room (room B) have been filling out a questionnaire. They do not know anything about these study instructions or that they have been paired with another person in another room, and they will not be told at any point during or after the study.

You have been given a copy of the study instructions given to the people in room B (attached).

When all the people in Room A have made their decisions, the experimenter takes the box marked "Mail" to an adjacent room. The experimenter records the contents of each envelope and adds the \$5 dollar participation fee for the person in room B.

The experimenter then takes the envelopes to Room B. The experimenter distributes the envelopes to the people in room B according to the pair numbers on their instructions. The people in room B then leave their room and the study is over. 


\section{Appendix C: Instructions for Study 2}

\section{INTRO FOR ALL GAMES}

Thank you for accepting this HIT. You have received \$0.20 for participating. You also have the opportunity to receive additional money as described below.

In this task, you will participate in a simple decision making study that lasts less than 2 minutes involving a very short (five question) survey.

When you finish the survey, you will receive a completion code in order to get paid. 


\section{[Giving game + Transfer action instructions]}

You have been randomly assigned to interact with another person who also completes this HIT. You will never know who this other person is, and they will never know who you are. You cannot participate in this HIT more than once.

You are an $\mathrm{X}(\mathrm{Y})$ person. All $\mathrm{X}$ and $\mathrm{Y}$ people have received these same instructions.

In this HIT you will play the giving game.

The giving game works as follows. Every X person starts with 100 cents.

Each X person has been randomly paired with a Y person.

The $\mathrm{X}$ person decides how much money out of the 100 cents, if any, to transfer to the $\mathrm{Y}$ person. Once this is decided, the $\mathrm{X}$ person will fill out a short questionnaire and then the $\mathrm{X}$ person is finished with the HIT. The $\mathrm{X}$ person will receive as a bonus any money not transferred.

Each Y person fills out the same questionnaire, and then is finished with the HIT. The Y person will receive as a bonus any money the $\mathrm{X}$ person transfers.

The HIT is then over for both people. The $\mathrm{X}$ and $\mathrm{Y}$ players never interact again, and never have a subsequent chance to affect each others' bonuses.

NEW PAGE

You are an X player. How much money out of the 100 cents do you want to transfer to the Y player?

Slider:

[ 0 ..... 100]

\section{OR}

You are a Y player. How much money out of the 100 cents do you think the X player will transfer to you?

Slider:

[ 0 ..... 100] 


\section{[Keeping game + Transfer action instructions]}

You have been randomly assigned to interact with another person who also completes this HIT. You will never know who this other person is, and they will never know who you are. You cannot participate in this HIT more than once.

You are an $\mathrm{X}(\mathrm{Y})$ person. All $\mathrm{X}$ and $\mathrm{Y}$ people have received these same instructions.

In this HIT you will play the keeping game.

The keeping game works as follows. Every X person starts with 100 cents.

Each X person has been randomly paired with a Y person.

The $\mathrm{X}$ person decides how much money out of the 100 cents, if any, to transfer to the $\mathrm{Y}$ person. Once this is decided, the $\mathrm{X}$ person will fill out a short questionnaire and then the $\mathrm{X}$ person is finished with the HIT. The $\mathrm{X}$ person will receive as a bonus any money not transferred.

Each Y person fills out the same questionnaire, and then is finished with the HIT. The Y person will receive as a bonus any money the $\mathrm{X}$ person transfers.

The HIT is then over for both people. The $\mathrm{X}$ and $\mathrm{Y}$ players never interact again, and never have a subsequent chance to affect each others' bonuses.

NEW PAGE

You are an X player. How much money out of the 100 cents do you want to transfer to the Y player?

Slider:

[ 0 ..... 100]

\section{OR}

You are a Y player. How much money out of the 100 cents do you think the X player will transfer to you?

Slider:

[ 0 ..... 100] 


\section{[Giving game + Give action instructions]}

You have been randomly assigned to interact with another person who also completes this HIT. You will never know who this other person is, and they will never know who you are. You cannot participate in this HIT more than once.

You are an $\mathrm{X}(\mathrm{Y})$ person. All $\mathrm{X}$ and $\mathrm{Y}$ people have received these same instructions.

In this HIT you will play the giving game.

The giving game works as follows. Every X person starts with 100 cents.

Each X person has been randomly paired with a Y person.

The $\mathrm{X}$ person decides how much money out of the 100 cents, if any, to give to the $\mathrm{Y}$ person. Once this is decided, the $\mathrm{X}$ person will fill out a short questionnaire and then the $\mathrm{X}$ person is finished with the HIT. The $\mathrm{X}$ person will receive as a bonus any money not given away.

Each Y person fills out the same questionnaire, and then is finished with the HIT. The Y person will receive as a bonus any money the $\mathrm{X}$ person chooses to give.

The HIT is then over for both people. The $\mathrm{X}$ and $\mathrm{Y}$ players never interact again, and never have a subsequent chance to affect each others' bonuses.

NEW PAGE

You are an X player. How much money out of the 100 cents do you want to give to the Y player?

Slider:

[ 0 ..... 100]

\section{OR}

You are a Y player. How much money out of the 100 cents do you think the $\mathrm{X}$ player will give to you?

Slider:

[ 0 ..... 100] 


\section{[Keeping game + Keep action instructions]}

You have been randomly assigned to interact with another person who also completes this HIT. You will never know who this other person is, and they will never know who you are. You cannot participate in this HIT more than once.

You are an $\mathrm{X}(\mathrm{Y})$ person. All $\mathrm{X}$ and $\mathrm{Y}$ people have received these same instructions.

In this HIT you will play the keeping game.

The keeping game works as follows. Every X person starts with 100 cents.

Each X person has been randomly paired with a Y person.

The $\mathrm{X}$ person decides how much money out of the 100 cents, if any, to keep. Once this is decided, the $\mathrm{X}$ person will fill out a short questionnaire and then the $X$ person is finished with the HIT. The $X$ person will receive as a bonus any money kept.

Each Y person fills out the same questionnaire, and then is finished with the HIT. The Y person will receive as a bonus any money the $\mathrm{X}$ person does not keep.

The HIT is then over for both people. The $\mathrm{X}$ and $\mathrm{Y}$ players never interact again, and never have a subsequent chance to affect each others' bonuses.

\section{NEW PAGE}

You are an X player. How much money out of the 100 cents do you want to keep for yourself?

Slider:

[ $0 \ldots . . .100]$

\section{OR}

You are a Y player. How much money out of the 100 cents do you think the X player will keep?

Slider:

[0 ..... 100] 


\section{QUESTIONNAIRE FOR ALL GAMES}

What is your gender?

What is your age?

Is English your first language?

How many hours a week would you estimate you spend doing on-line tasks for payment?

What country do you live in?

In order to facilitate our research, we are interested in knowing certain factors about you. Specifically, we are interested, in whether you actually take the time to read the directions; if not, then the data we collect based on your responses will be invalid. So, in order to demonstrate that you have read the instructions, please ignore the next question, and simple write "I read the instructions" in the box labeled "Any comments or questions?” Thank you very much.

How difficult did you find this survey?

Any comments or questions? 